\title{
Reimbursement of Drugs for Rare Diseases through the Public Healthcare System in Canada: Where Are We Now?
}

\author{
Remboursement, par le système de santé public \\ au Canada, des médicaments pour maladies rares : \\ où en sommes-nous?
}

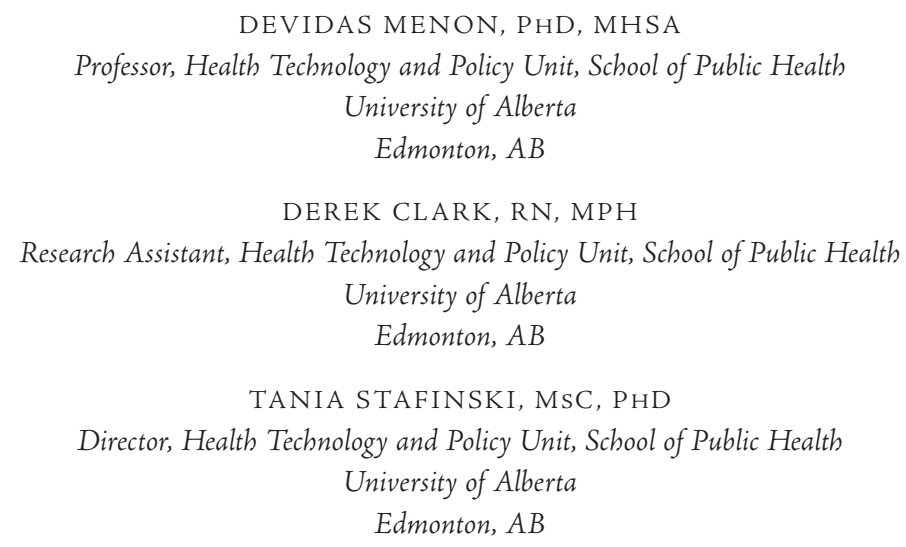

DEVIDAS MENON, PHD, MHSA

Professor, Health Technology and Policy Unit, School of Public Health

University of Alberta

Edmonton, $A B$

DEREK CLARK, RN, MPH

Research Assistant, Health Technology and Policy Unit, School of Public Health

University of Alberta

Edmonton, $A B$

TANIA STAFINSKI, MSC, PHD

Director, Health Technology and Policy Unit, School of Public Health

University of Alberta

Edmonton, $A B$ 


\begin{abstract}
Introduction: Over the past 20 years, the number of therapies developed for rare diseases has rapidly increased. Often, these therapies represent the only active treatment for debilitating and/or life-threatening conditions. However, they create significant challenges for public and private payers. Because they target small patient populations, clinical evidence of efficacy/ effectiveness is typically limited, while the cost per patient is high. In Canada, each province/territory establishes its own mechanisms for determining which drugs for rare diseases (DRDs) to provide.

Objectives: To compare current mechanisms across provinces and territories, and explore their impact on access.

Methods: A systematic review of relevant published and unpublished documents was performed. Electronic bibliographic databases, the internet, and government websites were scanned using structured search strategies. Information was extracted independently by two researchers, and included aspects such as program type, condition/patient/therapy eligibility criteria, role of health technology assessment (HTA), decision options, ethical assumptions, and stakeholder input. It was validated through member-checking with provincial/territorial policy experts and tabulated to facilitate qualitative analyses. Impact on access was assessed through a cross-province/territory comparison of the coverage status of all non-cancer therapies reviewed by the Common Drug Review for indications affecting $<1 / 2,000$ Canadians using the Kappa statistic. Reasons for variations were explored using qualitative techniques. Results: Each province/territory has formal and informal mechanisms through which such therapies may be accessed. In most cases, formal mechanisms constitute the centralized HTA processes that also apply to common therapies. While several provinces have established dedicated processes/programs, whether they have affected access is not clear. Despite broadly comparable approaches, there is less than perfect agreement on publicly funded DRDs across jurisdictions.

Conclusions: Individual jurisdictions have developed different approaches to providing access to these therapies. However, as the number increases, a more systematic approach to decisionmaking may be needed.
\end{abstract}

\title{
Résumé
}

Introduction: Au cours des vingt dernières années, le nombre de thérapies pour les maladies rares a augmenté rapidement. Ces thérapies représentent souvent le seul traitement actif pour des personnes aux prises avec un état débilitant ou mettant la vie en danger. Cependant, il y a d'importants défis pour les gouvernements et les tiers payant privés. Étant donné que ces thérapies visent un petit nombre de patients, il y a souvent peu de données cliniques sur leur efficience et leur efficacité, tandis que le coût par patient demeure élevé. Au Canada, chaque province ou territoire conçoit ses propres mécanismes pour déterminer quels médicaments pour les maladies rares (MMR) seront fournis. 
Reimbursement of Drugs for Rare Diseases through the Public Healthcare System in Canada: Where Are We Now?

Objectifs : Comparer, entre les provinces et les territoires, les mécanismes en place et étudier leur impact sur l'accès.

Méthodes: Nous avons mené une revue systématique des documents pertinents publiés et non publiés. Au moyen de stratégies de recherche structurées, nous avons scruté les bases de données bibliographiques, l'Internet et les sites Web des gouvernements. Deux chercheurs indépendants ont recueilli les données, notamment à l'aide de critères tels que le type de programmes, les critères d'admissibilité pour l'état, le patient ou la thérapie, le rôle de l'évaluation des technologies de la santé (ETS), les choix de décisions, les questions d'éthique et les commentaires exprimés par les intervenants. Les données ont été validées auprès d'experts des provinces ou territoires, puis tabulées afin d'en faciliter les analyses qualitatives. Nous avons évalué l'impact sur l'accès en comparant, entre les provinces et les territoires, la couverture pour toutes les thérapies pour les états non cancéreux, et ce, à l'aide du Programme commun d'évaluation des médicaments pour les indications touchant un nombre de Canadiens $<1 / 2$ 000, au moyen de l'indice Kappa. Les causes des variations ont été explorées au moyen de techniques qualitatives.

Résultats: On trouve, dans chaque province et territoire, des mécanismes officiels et non officiels qui permettent d'accéder aux thérapies. Dans la plupart des cas, les mécanismes officiels sont les mêmes processus d'ETS centralisés qui sappliquent également aux thérapies communes. Bien que plusieurs provinces aient mis en place des processus et des programmes particuliers, on ne sait pas clairement s'ils ont une influence sur l'accès. Malgré des démarches similaires dans l'ensemble, il n'y a pas vraiment d'accord entre les divers gouvernements sur le financement public des MMR.

Conclusions : Chaque province et territoire a développé une démarche différente pour ce qui est de l'accès à ces thérapies. Toutefois, alors que le nombre de cas augmente, la prise de décisions devrait adopter une démarche plus systématique.

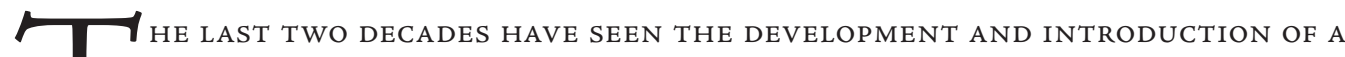 number of innovative drugs for rare diseases (DRDs) (i.e., orphan or ultra-orphan (drugs). In many cases, they comprise the first disease-modifying treatment for a} life-threatening or chronically debilitating complex disease. Therefore, patients and families want access to them as soon as possible. However, for payers, the risks associated with coverage decisions on DRDs are considerable. Clinical evidence is typically limited to small short-term trials relying on surrogate rather than hard clinical outcomes (Picavet et al. 2013). The annual treatment costs, most of which are life-long, can exceed $\$ 300,000 \mathrm{CDN}$ per patient (Hollis 2005). Thus, given uncertainty in the value proposition, payers are reluctant to reimburse DRDs. Often, a positive coverage decision follows an extensive media campaign highlighting the plight of desperate patients and demonizing payers. Kalydeco ${ }^{\circledR}$ for some types 
of cystic fibrosis provides a recent Canadian example of the tensions between patients and payers (CTV News 2014). In Canada, the absence of national pharmacare has been cited as one factor contributing to those tensions, as there may be disparities in access to DRDs across provinces/territories that potentially create inequities in the health of patients with rare diseases. In response, provincial and territorial ministers of health have announced plans to consider a national approach to reimbursement decision-making on DRDs (Canadian Intergovernmental Conference Secretariat 2015). However, before exploring what that approach might look like, it is important to understand how these decisions are currently made and the extent to which access to DRDs actually varies across Canada.

While published literature describing Canada's centralized processes for providing reimbursement recommendations to participating federal and provincial drug plans exists (Grima and Samjoo 2013; Rocchi et al. 2012; Spitz 2013), a comprehensive review of how decisions on DRDs are made and through what mechanisms DRDs are accessed the provincial and territorial drug plan level has yet to be published.

\section{Objective}

The objectives of this paper are:

1. To compare current mechanisms for making reimbursement decisions on DRDs across provincial and territorial publicly funded drug plans in Canada.

2. To examine the extent to which reimbursement of DRDs through publicly funded drug plans varies across provinces and territories.

\section{Background}

In Canada, new drugs (including DRDs) being considered for reimbursement through provincial (except for Quebec), territorial or federal drug plans (i.e., outpatient) must first be evaluated by one of two centralized drug review processes: the Common Drug Review (CDR) for non-oncology drugs and the pan-Canadian Oncology Drug Review for oncology drugs. Both are managed by the Canadian Agency for Drugs and Technologies in Health (CADTH) and evaluate the clinical and economic implications of drugs submitted for review and provide reimbursement recommendations to participating drug plans. Currently, there are no separate centralized review processes or explicit special considerations within the two existing ones for DRDs. Decisions on whether to reimburse a drug remain with each plan. Therefore, this paper focuses on decision-making processes at the provincial and territorial levels. Further, since most of the life-long drugs with annual per-patient costs exceeding \$100,000 Canadian dollars target non-cancers, only processes for non-cancer drugs are described.

\section{Methods}

The project was conducted in two parts. The first involved the identification of different ways in which patients access DRDs through the publicly funded healthcare system in each 
Reimbursement of Drugs for Rare Diseases through the Public Healthcare System in Canada: Where Are We Now?

province and territory and through the federal government's Non-insured Health Benefits (NIHB) program. The second examined variations in access to specific DRDs across provinces and territories, and explored whether those variations may be related to differences in decision-making processes.

In this project, a DRD was defined as a drug intended to treat a disease with a prevalence of $<1 / 2,000$ persons, the rate recently proposed in the draft regulatory framework for orphan medicinal products prepared by Health Canada (Health Canada 2012a).

\section{Part 1: Identification of mechanisms for accessing DRDs through the publicly funded healthcare systems}

To identify current mechanisms through which reimbursement decisions on DRDs are made, three methods were used:

1. a comprehensive review of published papers and government documents describing provincial and territorial approaches to providing access to DRDs;

2. analyses of relevant ministerial websites; and

3. a survey of drug plan managers in each of the provinces and territories.

\section{COMPREHENSIVE LITERATURE REVIEW}

The literature search included the following bibliographic databases: PubMed, The Cochrane Library, the Centre for Reviews \& Dissemination (DARE, NHS EED and HTA) databases, EMBASE, Web of Knowledge, EconLit, PAIS International, Sociological Abstracts, Canadian Business and Current Affairs, ABI/INFORM Global, Scopus, Proquest Dissertations \& Theses and Canadian Newsstand Complete. The databases were searched in February-March 2013. The search was restricted to publications from 1990 to date, and English or French language publications (where possible). Search terms used controlled vocabulary, such as the Medical Subject Headings (MeSH) terms: Rare Diseases, or Orphan Drug Production, as well as additional MeSH and free text keywords (to capture the concepts of decision-making, reimbursement, etc.). Monthly PubMed update searches were run throughout the project (to March 2015).

Searches for grey literature included the following Internet sources: KU-UC (Quebec Population Health Research Network), Google.ca and the websites of rare diseases associations and Canadian federal and provincial government agencies. The reference lists of relevant papers were scanned to identify additional references. Full details of the search terms and sources used are included in Appendix A. For each of the Internet searches, the first 300 "hits" were examined. Citations identified through the various searches were imported into a Reference Manager database. Two researchers independently reviewed all of the citations using a set of pre-defined selection criteria that included the names of the provinces and territories and discussion of coverage or reimbursement for specific DRDs/orphan drugs or DRDs/orphan drugs, in general. Agreement between researchers was assessed using the 
kappa statistic, and discrepancies were resolved through discussion. This statistic, which measures agreement beyond chance between sets of observations (i.e., which papers to include in the review), was used. Kappa values range from -1 to 1 , and strength of agreement is interpreted as follows: $\mathrm{K}<0$ (poor); $0<\mathrm{K}<0.20$ (slight); $0.21<\mathrm{K}<0.40$ (fair); $0.41<$ $\mathrm{K}<0.60$ (moderate); $0.61<\mathrm{K}<0.80$ (substantial); and $0.81<\mathrm{K}<1.0$ (almost perfect) (Fleiss 1981). Information on key elements from papers selected for inclusion was extracted using a standard "data abstraction form." The key elements, identified as relevant by senior policy makers from several provinces involved in a Canadian Institutes for Health Research (CIHR)-funded team grant on policies for managing rare diseases in Canada, included: type of reimbursement program (e.g., listing on a formulary or case-by-case/exceptional funding), decision options, condition/patient/therapy eligibility for consideration under a particular reimbursement program, role of clinical and economic evidence in reimbursement decisionmaking around DRDs and opportunities for stakeholder input (e.g., patients and specialists in rare diseases). These were defined on the basis of consultations with provincial drug plan managers and knowledge users in a CIHR-funded emerging team grant on policies for managing technologies for rare diseases. The extracted information was tabulated to facilitate qualitative comparative analyses.

\section{ANALYSES OF MINISTERIAL WEBSITES}

The website of each provincial and territorial ministry of health was scanned independently by two researchers to identify reimbursement processes for DRDs. The same data abstraction form as that developed for the literature review was used to systematically extract information from each website. The information was then combined with data collected from the literature review into a single set of tables.

\section{SURVEY OF DRUG PLAN MANAGERS}

Provincial/territorial/NIHB drug plan managers were contacted by e-mail to identify one individual from each jurisdiction who would be able to complete a self-administered survey. One representative from each jurisdiction participated. For each jurisdiction, a table of information about programs specific to DRDs and processes through which reimbursement decisions are currently made (obtained from the literature review and ministry websites) was prepared. This was sent to drug plan managers or their delegates for verification and updating. Based on feedback received, the tables were revised and then analyzed qualitatively. The survey questions from which these tables were prepared are shown in Appendix B.

\section{Part 2: Access to specific DRDs across provinces and territories}

To compare inter-provincial/territorial access to DRDs, a list of potential drugs was first compiled. It contained all DRDs (non-cancer) submitted to the CDR since its inception until February 2014. Because drugs must first go through these processes before being considered by provincial and territorial drug plans, CDR submissions were used as the information 
Reimbursement of Drugs for Rare Diseases through the Public Healthcare System in Canada: Where Are We Now?

source for identifying possible drugs. Canadian estimates of prevalence for the condition/disease indicated on each drug submission were obtained through targeted searches of Orphanet and published literature, as well as contact with patient organizations. Only drugs for which the prevalence of their indication was less than 1 in 2,000 individuals in Canada were selected. As no common definition of a "rare" disease exists in Canada, this prevalence rate, which is enshrined in European Union legislation, and being considered within the proposed Orphan Drug regulatory framework for Canada, was used. The selected drugs were then categorized by Anatomical, Therapeutic and Chemical (ATC) Classification.

Publicly funded coverage for/access to each included DRD across the provinces and territories was determined through a review of the contents of publicly available formularies and benefits lists and a survey of provincial and territorial drug plan managers. The survey listed all of the DRDs and asked respondents to indicate the reimbursement status of each one.

To assess variations in access to DRDs across jurisdictions, the kappa statistic, which measures agreement beyond chance between sets of observations (i.e., reimbursement status of drugs in each jurisdiction), was used. Kappa values were calculated for all of the included DRDs, as a whole, as well as for specific ATC Classification groups. The latter analysis was performed to assess whether concordance across plans varied across drug classes.

\section{Results}

\section{Part 1: Identification of mechanisms for accessing DRDs through the publicly funded bealthcare systems}

There was "almost perfect" agreement between the two reviewers in the sources of information selected $(K=0.92)$. Information on current mechanisms through which DRDs are considered for reimbursement was found for all 10 provinces, Nunavut, Yukon, the Northwest Territories and the NIHB program of the federal government. Although the searches of grey literature provided a considerable amount of information on specific jurisdictional processes, the survey of the jurisdictions yielded considerably more information from Alberta, British Columbia, Newfoundland, Nova Scotia, Saskatchewan and the NIHB program. The reimbursement decision-making mechanisms were grouped into three categories: (1) general reimbursement; (2) case-by-case review; and (3) DRD-specific plans or processes.

\section{GENERAL REIMBURSEMENT}

General reimbursement refers to processes established for making formulary decisions (i.e., decisions around whether or not to add a drug to the list of publicly insured drugs) for outpatient drugs, in general. All jurisdictions have such processes, which typically accept submissions from manufacturers following completion of a review by the CDR (Table 1 ). Thus, drugs (including DRDs) eligible for consideration are those for which a CDR recommendation is available. Across jurisdictions, possible outcomes of these processes are: (1) provide coverage through public funding, (2) provide coverage with conditions (e.g., specific patients 
or prescribing physicians) and (3) do not provide coverage (Table 1). All require information on the disease/condition for which the drug is indicated, clinical evidence addressing safety and effectiveness and economic evidence related to cost-effectiveness, price and budget impact (Table 2). Most of this information is contained within the original manufacturer's CDR submission. Requirements do not differ between DRDs and drugs for common conditions/diseases. In British Columbia (BC Ministry of Health 2010a), Ontario (MOHLTC 2013a) and Quebec (INESSS 2014b), perspectives of patients and families, provided through submissions from patient organizations, also comprise an information input. These submissions are accepted for all drugs under review, regardless of their indication. Some jurisdictions require letters from manufacturers confirming their ability to supply the drug based on the anticipated demand, e.g., Alberta (Alberta Health and Wellness 2012), Ontario (MOHLTC 2000) and Saskatchewan (Saskatchewan Health 2014c). In most jurisdictions, information inputs are collectively scrutinized by an expert committee, whose membership, at a minimum, comprises pharmacists and physicians (Table 3). In Ontario (Ontario Public Appointments Secretariat 2013b), British Columbia (BC Ministry of Health 2010a) and Quebec (INESSS 2014b), the committee also includes representatives from the public, referred to as "lay" members or "citizen" members depending on the jurisdiction. Each committee considers a set of decision factors/criteria and formulates a listing recommendation. In almost all jurisdictions, final decisions are made by the minister. Factors/criteria considered by all committees include recommendations from the CDR, therapeutic advantage, clinical safety and effectiveness, availability of alternatives and value for money (Table 3). Additionally, several committees explicitly consider: impact on patients (Alberta, Alberta Health and Wellness 2012; British Columbia, BC Ministry of Health 2014d; Ontario, MOHLTC 2013c; Quebec, INESSS 2014b; and Saskatchewan, Saskatchewan Health 2014c), current clinical practice/utilization patterns (Alberta, Alberta Health and Wellness 2012, and British Columbia, BC Ministry of Health 2014d), affordability (Alberta, Alberta Health and Wellness 2012; Manitoba Health 2014a; New Brunswick, Government of New Brunswick 2014f; Newfoundland, Newfoundland \& Labrador 2013d; and Ontario, MOHLTC 2013e), alignment with government goals/priorities (Alberta, Alberta Health and Wellness 2012; New Brunswick, Government of New Brunswick 2014f; Newfoundland, Newfoundland \& Labrador 2013d; Ontario, MOHLTC 2013e; and Saskatchewan, Saskatchewan Health 2014c), impact on health services (Ontario, MOHLTC 2013e; Newfoundland, Newfoundland \& Labrador 2013d; and Quebec, INESSS 2014b) and social values/ethical implications (British Columbia, BC Ministry of Health 2010a; Ontario, MOHLTC 2012m; and Quebec, INESSS 2007a). Importantly, in all jurisdictions, factors/criteria considered are the same for all drugs (including DRDs). Similarly, where formal opportunities to appeal decisions exist (British Columbia, BC Ministry of Health 2014g; Manitoba Blue Cross 2014c; Newfoundland, Newfoundland \& Labrador 2013d; Ontario, MOHLTC 2012m; Quebec, RAMQ 2014i; Saskatchewan; and the Yukon, Government of Yukon 2005), they apply to all drugs, regardless of their indication (Table 4). While decisions arising from general reimbursement review processes are made publicly 
Reimbursement of Drugs for Rare Diseases through the Public Healthcare System in Canada:

Where Are We Now?

available (usually through ministry websites) in most jurisdictions, rationales are not, with the exception of Alberta, Ontario and Quebec (INESSS 2007a). Tables 1 through 4 can be seen at www.longwoods.com/content/24360.

\section{CASE-BY-CASE REVIEW}

In almost all jurisdictions, drug plans have established processes for considering funding requests for drugs not included on the benefit list/formulary for individual patients (i.e., caseby-case review). Typically, requests are made by the prescribing physician, who completes an application form. Some jurisdictions have defined eligibility criteria related to the patients or drugs for review through these processes (Alberta, CTV News 2012; Manitoba Health 2008; MOHLTC 2011a; Prince Edward Island, PEI Ministry of Health and Wellness 2013f; Quebec, INESSS 2014j). With respect to patient-related criteria, all of these jurisdictions have a "lack of available treatment alternatives" condition, where patients considered are those who were unable to tolerate standard therapy or who did not achieve a satisfactory response to standard therapy. Drug-related criteria include drugs without regulatory approval, those yet to be reviewed through the general reimbursement process (Alberta, CTV News 2012, and Ontario, MOHLTC 2011a) or those failing to receive a positive recommendation through the general reimbursement process (New Brunswick, Government of New Brunswick 2014f; Newfoundland, Newfoundland \& Labrador 2013d; Ontario, MOHLTC 2011a). In Alberta, the annual cost must also exceed $\$ 100,000$ Canadian. "Rarity" of the disease is explicitly taken into account in Manitoba (Manitoba Health 2008) and Saskatchewan (Saskatchewan Health $2014 \mathrm{k}$ ), where "exception status drugs" can include those "not ordinarily prescribed or administered" in the province because the condition is "rarely found" there. However, it does not constitute an eligibility criterion. Across all jurisdictions, potential decision options/outcomes comprise "provide coverage with conditions" or "do not provide coverage." The "conditions" are generally clinically based. In several jurisdictions, a "provide coverage with conditions" is an interim decision, granting temporary funding/access for a fixed period (Table 1). In all jurisdictions, the decision applies to the individual patient for whom the DRD was requested (i.e., DRD is not added to the formulary).

Information requirements of case-by-case requests are less explicit, except in Alberta and Ontario (34), where submission of relevant peer-reviewed clinical studies is specified (Table 2). Procedures for making case-by-case decisions are also less explicit. In both Alberta and Ontario (MOHLTC 2011a), decision-making involves senior-level staff (executive directors), who seek advice from external clinical experts (Table 3). In most jurisdictions, decision criteria/factors considered during deliberations are not specified.

\section{DRD-SPECIFIC PLANS AND PROCESSES}

Five provinces have established specific programs for DRDs. These programs take the form of coverage plans enabling access to a defined set of DRDs on a separate formulary in Alberta (Alberta Health 2012b) and New Brunswick (Government of New Brunswick 2014l) or 
dedicated reimbursement decision-making processes for DRDs (British Columbia; Ontario, MOHLTC 2013c; and Saskatchewan). Alberta's program covers CDR-reviewed drugs for genetic lysosomal storage disorders affecting fewer than 1 in 50,000 individuals in Alberta (Alberta Health 2012b). Similar to a case-by-case review, a physician who specializes in these disorders completes a Rare Disease Drug Coverage application on behalf of a patient. The application is considered by the same committee as that involved in the general reimbursement process, but with advice from an expert clinical panel on rare diseases (Alberta Rare Diseases Clinical Review Panel). Two recommendations are possible: "provide coverage with conditions" or "do not provide coverage." A "provide coverage with conditions" involves coverage conditional upon regular monitoring of clinical outcomes. If his/her condition worsens, coverage is discontinued. A "do not provide coverage" recommendation is made if a patient has an additional significant illness that is likely to substantially reduce life expectancy (Table 1). Final decisions rest with the Minister of Health. Importantly, this program only applies to a set of drugs that have already been deemed eligible. Since 2009, it has included drugs for the following diseases: Gaucher, Fabry, MPS II (Hunter Syndrome) and Pompe. Like Alberta's program, the recently announced Drugs for Rare Diseases Plan in New Brunswick also applies to a defined set of drugs/separate formulary (Government of New Brunswick 20141). That set comprises five drugs for the following diseases: MPS I, MPS II, CryopyrinAssociated Periodic Syndrome, Pompe disease and Niemann Pick Type C (Government of New Brunswick 2014, 2014u). Similar to Alberta's program, coverage is considered for individual patients whose physician has submitted a request on their behalf. However, the plan will adopt criteria from Ontario's Drugs for Rare Diseases Evaluation Framework (DRDEF) (Government of New Brunswick 2014l, 2014u). This framework represents one of two provincial reimbursement decision-making processes dedicated to rare diseases only. Drugs eligible for review through the DRDEF are those that treat diseases (non-cancer-related) with an annual incidence of $<1 / 150,000$ individuals and those for which clinical trials measuring clinically important outcomes have not been possible (Fraser 2013). Requests for consideration of an eligible drug may be submitted by manufacturers or physicians using a standard template (MOHLTC 2011c). Unlike the plans in both Alberta (Alberta Health 2012b) and New Brunswick (Government of New Brunswick 20141), requests relate to access for all patients for whom the drug is indicated, rather than access for an individual patient. Required information includes a description of the disease (incidence, natural history, subtypes and available treatment alternatives), proposed drug benefit price, letter confirming ability to supply anticipated demand, clinical trial data and a budget impact analysis (Fraser 2013). Submissions are reviewed by the Drugs for Rare Diseases Working Group (DRDWG), comprising physicians, a pharmacist and a health economist (Winquist et al. 2012). The DRDWG confirms disease prevalence and that adequately powered studies are infeasible; reviews the pathophysiology, natural history and health implications; considers the mechanism of action of the drug and its potential and actual treatment effects; reviews available clinical data and develops a decision model that incorporates variability in treatment effects; 
Reimbursement of Drugs for Rare Diseases through the Public Healthcare System in Canada: Where Are We Now?

and evaluates the budget impact of the drug. It also considers patient submissions prepared by registered patient advocacy groups (MOHLTC 2013c). Based on this information, the DRDWG makes a funding recommendation, which is forwarded to the Executive Officer for a decision (Fraser 2013; Winquist et al. 2012). Two decision options exist: "provide coverage with conditions" (regular monitoring of patient outcomes) and "do not provide coverage." While there is no formal appeals mechanism, patient organizations, physicians and manufacturers may provide feedback to the Ministry and DRDWG, who, in turn, determine whether a re-evaluation is necessary (Winquist et al. 2012). In contrast to the rare disease plans in Alberta (Alberta Health 2012b) and New Brunswick (Government of New Brunswick 2014l), the status of submissions and decisions are publicly available on the ministry's website (MOHLTC 2013c). As in Ontario, British Columbia's Expensive Drugs for Rare Diseases (EDRD) program also comprises a process for making reimbursement decisions on DRDs. However, unlike the DRDEF, reimbursement requests are made by physicians for specific patients and reviewed on a case-by-case basis. Drugs eligible for review must have an annual cost of $>\$ 50,000 /$ patient and be indicated for a non-cancer-related condition with a prevalence of $<1.7 / 100,000$ Canadians (Table 1 ). Requests are reviewed by an expert committee (EDRD Advisory Committee), comprising pediatric and adult rare disease specialists, a medical geneticist, pharmacists, health administrators, a health economist and an ethicist. The committee considers severity of the disease, clinical effectiveness of the drug and availability of alternatives (Table 3). Recommendations are either: "provide coverage with conditions" or "do not provide coverage," and final decisions are made by the minister. Decisions are not posted on the ministry's website. Saskatchewan's EDRD process is similar to British Columbia's program, except that eligible drugs are those used to treat conditions with an annual incidence of $<1 / 150,000$ individuals in Canada. As in British Columbia, requests relate to individual patients and are made by their physicians. The Saskatchewan Drug Plan and its Drug Advisory Committee review requests, considering an explicit set of factors that include recommendations from the CDR, criteria from the Ontario EDRDEF and reimbursement status of the drug in other Canadian jurisdictions (Table 3). Decision options are "provide coverage with conditions" and "do not provide coverage" to the patient. "Conditions" comprise fixed periods at the end of which a progress report describing the patient's treatment response must be provided (Table 3).

\section{Part 2: Access to specific DRDs across provinces and territories}

A total of 33 DRDs met the selection criteria and were included in the analyses (Table 5). While 11 (33\%) were available through one of the above three types of reimbursement mechanisms in at least 10 of the jurisdictions, 12 (36\%) were available in fewer than three of the jurisdictions. Of those 12, over half fell within the Alimentary Tract and Metabolism Products ATC Classification. Overall, there was moderate agreement (pooled $\mathrm{K}=0.48$ ) on DRD accessibility across the jurisdictions. However, kappa scores ranged from 0.11 (between Yukon and Ontario) to 1.0 (between Nunavat and Northwest Territories) (Table 6). 
Among pair-wise jurisdictional comparisons, the proportion of kappa scores indicating "substantial," "moderate" and "slight" agreement was 20\%, 40\% and 5\%, respectively (Table 6 ). Based on kappa patterns, level of agreement did not appear to vary with the presence of a DRD-specific reimbursement process (i.e., higher scores were not observed between jurisdictions with such processes). When agreement across jurisdictions was assessed by ATC Classification, over half of the kappa scores were less than 0.2 , indicating "slight" agreement across jurisdictions (Table 7). The lowest scores related to Alimentary Tract and Metabolism Products (which include the enzyme replacement therapies) and Respiratory System Agents (ivacaftor). Tables 5 through 7 can be seen at www.longwoods.com/content/24360.

\section{Discussion}

In this paper, the landscape of approaches used by publicly funded drug plans to make reimbursement decisions on DRDs across provinces and territories is described. All jurisdictions use a combination of general reimbursement review processes through which formulary listing decisions are typically made and "safety-net" programs through which case-by-case requests for access for individual patients are determined. Moreover, all use similar types of clinical and economic evidence (usually provided by the CDR) to inform listing decisions. Despite broadly comparable approaches, there is less than perfect agreement on publicly funded DRDs across jurisdictions. This may be explained in part by variations in factors considered during decision-making beyond clinical and economic implications. As many rare diseases are genetic and found predominantly within certain communities and geographic locations, demand for specific DRDs may differ across jurisdictions. Therefore, the lack of coverage in a particular province or territory may reflect a lack of patients for whom the DRD is indicated. For example, the prevalence of Fabry Disease in Nova Scotia (which has a founder population with the disease) has been reported to be 1 in 15,000 (West et al. 2002), while the prevalence in a general population ranges between 1 in 40,000 and 1 in 117,000 . Therefore, a drug may receive a higher priority for funding from decision-makers in some jurisdictions where the disease is more prevalent (or the drug may not even be considered in a province where there are no patients with the disease). It may also be related to cost. DRDs around which variations in access across Canada were found to be the greatest include some of the most expensive drugs currently marketed (ivacaftor, with annual costs estimated at over $\$$ US300,00, and eculizumab, with annual costs exceeding \$US500,000).

Variations in access to drugs across Canada have been previously documented in the literature (Chafe et al. 2011; Glass-Kaastra et al. 2014; Menon et al. 2005). These differences raise questions around inequities in access because of the limited treatment choice. For common diseases, a number of treatment options exist, at least one of which is available in jurisdictions. Variations in access may also be related to media coverage of individual patients seeking reimbursement for a particular DRD in a specific jurisdiction. A national approach may address some of these inter-jurisdictional disparities, as well as other issues related to rare diseases, such as an inconsistency in the definition of a rare disease, and challenges related to 
Reimbursement of Drugs for Rare Diseases through the Public Healthcare System in Canada: Where Are We Now?

establishing patient registries with small numbers of patients in each jurisdiction (Panju and Bell 2010).

In April 2008, the House of Commons passed a motion to create a national plan for rare diseases (49). While such a plan has yet to be developed, federal, provincial and territorial governments have begun to examine ways to address issues around DRDs collaboratively. Under the umbrella of the Council of the Federation, premiers have established a working group to explore ways to manage the cost of DRDs with evidence-based approaches (Canadian Intergovernmental Conference Secretariat 2015). At the federal government level, the Minister of Health announced in 2102 that an Orphan Drug Regulatory framework would be established for the pre-market review and post-market monitoring of new DRDs (Health Canada 2012a). However, this framework has yet to be implemented.

Another Canadian initiative has been the creation of the pan-Canadian Pharmaceutical Alliance ( $\mathrm{pCPA}$ ) by the provincial and territorial governments. The pCPA has the authority to decide whether pan-Canadian negotiations should occur after a new drug, including a DRD, has undergone the common drug review. Such negotiations may involve proposals of "managed access programs," in which a drug is funded with the requirement that additional evidence be collected during its use (i.e., access with evidence development). Given that many DRDs are launched with limited clinical evidence, this might be the most appropriate approach to providing more DRDs through public drug plans. As these initiatives move forward, it will be important to ensure that they take into account inter-jurisdictional differences in the needs of patients. The results of this study could inform further development of the $\mathrm{pCPA}$ as well as policies related to managed access programs.

\section{Limitations}

This project relied on publicly available information and survey responses. Although copies of tables were sent to each jurisdiction to ensure their accuracy and comprehensiveness, it is possible that some information may have been missed. Also, processes may have changed in the months following completion of data collection. Finally, some of the more subtle aspects of decision-making may not have been captured through the data collection that was undertaken from the jurisdictions.

\section{Conclusion}

Despite broadly similar coverage review processes for DRDs across Canada, listing decisions and, in turn, access vary considerably. Given the recent interest expressed in orphan drug policy by both levels of government in Canada, an opportunity might exist to build on these review processes and create a pan-Canadian approach.

\section{Acknowledgements}

The authors would like to thank Leigh-Ann Topfer and Lynne Lacombe for their assistance with the literature searches. The authors are also grateful to Alexa Nardelli and Andrea 
Dunn for assistance with data extraction. This study was funded through an Emerging Team Grant from the Canadian Institutes of Health Research on "Developing Effective Policies for Managing Technologies for Rare Diseases."

Correspondence may be directed to: Devidas Menon, Professor, Health Technology and Policy Unit, School of Public Health, University of Alberta, 3032 Research Transition Facility; 8308-114 St., Edmonton, AB T6G2V2; e-mail: menon@ualberta.ca

\section{References}

Alberta Health. 2008b. Alberta Rare Diseases Drug Program Fact Sheet. Retrieved May 20, 2015. <http://www. health.alberta.ca/documents/Pharma-Strategy-2008-rare-disease.pdf >.

Alberta Health Services. 2011d. Medical Director, Pharmacy Services - Short Term Exception Drug Therapy. Position Summary. <http://www.albertahealthservices.ca/hp/if-hp-phys-med-dir-pharmacy-stedt-role-description.pdf>.

Alberta Health. 2012c. Budget Impact Assessment for the Alberta Drug Benefit List. Retrieved May 20, 2015. <https://www.ab.bluecross.ca/dbl/pdfs/bia2012.pdf>.

Alberta Health. 2012e. "Section 4 - Rare Diseases Drug Coverage Program.” In Alberta Health and Wellness Drug Benefit List (pp. 4.1-4.3). Retrieved 20 May 2105. <https://www.ab.bluecross.ca/dbl/pdfs/dbl_july_list.pdf>.

Alberta Health and Wellness. 2012. Drug Benefit List. Retrieved May 20, 2105. < https://www.ab.bluecross.ca/dbl/ pdfs/dbl_july_list.pdf $>$.

Alberta Health. 2014m. Specialized High Cost Drug Program. Retrieved May 20, 2015. <http://www.health.alberta. ca/services/drugs-high-cost.html>.

Bennett, D. 2013. "Alberta to Fund Treatment for Girl, 3, with Rare Enzyme Deficiency." Globe and Mail. August 12. <http://www.theglobeandmail.com/news/national/alberta-to-fund-treatment-for-girl-3-with-rare-enzymedeficiency/article13715024/>.

British Columbia Ministry of Health. 2004. “Drugs Under Review.” Pharmacare Newsletter 4(8): 6-8. Retrieved May 20, 2015. <http://www2.gov.bc.ca/gov/topic.page?id=44CD3389BFA14173979CF45D6521FEC3>.

British Columbia Ministry of Health. 2010a. "The Drug Review Process in B.C. - Overview." Retrieved May 20, 2015. <http://www2.gov.bc.ca/gov/topic.page?id=5AFC31A2ECFF4443AFACBB36A0BF2EA0>.

British Columbia Ministry of Health. 2012f."Special Authority Request: Deferasirox Coverage Initial and Renewal." Retrieved May 20, 2015. <http://www2.gov.bc.ca/gov/topic.page?id=B5427BF4780F4A2A939502244 4A67B39>.

British Columbia Ministry of Health. 2014g. "Sponsor Engagement in the Drug Review Process." Retrieved May 20, 2015. <http://www2.gov.bc.ca/gov/topic.page?id=AD8E4224D5FE4ACA905154B384914934>.

British Columbia Ministry of Health. 2014p. “Patented Drug Products Reviewed by the CDR (New Drugs, New Combination Products and Drugs With New Indications)." Submission Requirements. Retrieved May 20, 2015. <http://www2.gov.bc.ca/gov/topic.page?id=AD8E4224D5FE4ACA905154B384914934>.

British Columbia Ministry of Health. 2014o. “Drug Review Process." Retrieved May 20, 2015. <http://www2.gov. bc.ca/gov/topic.page?id=D1A5394E2B5F4A358A65C07D202E8955>.

British Columbia Ministry of Health. 2014q. Priority Review. Retrieved May 20, 2015. <http://www2.gov.bc.ca/ gov/topic.page?id=AD8E4224D5FE4ACA905154B384914934>.

Canadian Intergovernmental Conference Secretariat. 2015. Press Release - Provinces and Territories Talk Health Care. Retrieved May 20, 2015. <http://www.scics.gc.ca/english/conferences.asp?a=viewdocument\&id=2217>.

CancerCare Manitoba. 2012k. Home Cancer Drug Program. Retrieved May 20, 2015. <http://www.cancercare.

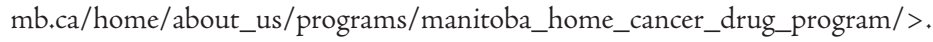

Chafe, R., A. Culyer, M. Dobrow, P.C. Coyte, C. Sawka, S. O’Reilly et al. 2011. “Access to Cancer Drugs in Canada: Looking Beyond Coverage Decisions. Healthcare Policy 6(3): 27-36. 


\section{Reimbursement of Drugs for Rare Diseases through the Public Healthcare System in Canada: Where Are We Now?}

Croix Bleu Medavie. 2010b. Objet: Médicament d'exception et Patient d'exception Informations et Procédure de Réclamation. Retrieved May 20, 2015. <http://www.drh.umontreal.ca/documents/avantages_sociaux/medicament_patient_exception.pdf $>$.

CTV News. 2012. "New Program for Pricey Drugs." Retrieved May 20, 2015. <http://calgary.ctvnews.ca/newprogram-for-pricey-drugs-1.776050>.

CTV News. 2014. "Alberta Reaches Tentative Deal on Cystic Fibrosis Drug on Behalf of Provinces." Retrieved May 20, 2015. <http://www.ctvnews.ca/health/alberta-reaches-tentative-deal-on-cystic-fibrosis-drug-on-behalf-ofprovinces-1.1846955>.

Fleiss, J.L. 1981. Statistical Methods for Rates and Proportions (2nd ed.). New York, NY: John Wiley \& Sons, Inc. Fraser, B. 2013. Evidentiary and Decision Making Challenges in the Context of Rare Diseases: Provincial Program Perspective. Ottawa: Canadian Agency for Drugs and Technologies in Health (CADTH). Retrieved May 20, 2015. <http://www.cadth.ca/media/symp-2013/2013-presentations/A5-Ontario\%20DRD\%20Framework\%20 CADTH\%20presentation-Fraser-Salon\%20D.pdf>.

Glass-Kaastra, S.K., R. Finley, J. Hutchinson, D.M. Patrick, K. Weiss, and J. Conly 2014.“Does Variation Among Provincial Drug Formulary Antimicrobial Listings in Canada Influence Prescribing Rates?" PLoS One 9(9): e107515. < http://www.ncbi.nlm.nih.gov/pmc/articles/PMC4159347/>.

Government of Manitoba. 2012. "Budget 2012: Province to Provide Free Cancer Drugs for all Patients." Press Release. Retrieved May 20, 2015. <http://news.gov.mb.ca/news/?item=13772>.

Government of New Brunswick. 2014f. Special Authorization. Retrieved May 20, 2015. <http://www.gnb. ca/0212/SpecialAuthorization-e.asp >.

Government of New Brunswick. 2014l. New Brunswick Drugs for Rare Diseases Plan. Retrieved May 20, 2015. $<$ http://www2.gnb.ca/content/gnb/en/departments/health/services/services_renderer.201352.New_Brunswick_ Drugs_for_Rare_Diseases_Plan.html>.

Government of New Brunswick. 2014s. "Rare Diseases Drug Plan Established." News Release. Retrieved May 20, 2015. <http://www2.gnb.ca/content/gnb/en/news/news_release.2014.07.0939.html>.

Government of New Brunswick. 2014u. New Brunswick Prescription Drug Program formulary/Formulaire du plan de Médicaments sur Ordonnance du Nouveau-Brunswick. Retrieved May 20, 2015. <http://www.gnb.ca/0212/ nbpdpformulary-e.asp>.

Government of the Northwest Territories. 1998. Extended Health Benefits. Retrieved May 20, 2015. <http://www. hss.gov.nt.ca/health/nwt-health-care-plan/extended-health-benefits-specified-disease-conditions >.

Government of the Northwest Territories. 2008c. "NWT Clinical Practice Information Notice." Retrieved May 20, 2015. <http://www.hss.gov.nt.ca/information-health-professionals/clinical-practice-information-cpi-notices > .

Government of the Northwest Territories. 2011f."Extended Health Benefits Program. Exception Approval Drug Request." Retrieved May 20, 2015. <http://www.hss.gov.nt.ca/sites/default/files/ehb_request_for_exception_ drug_coverage_0.pdf $>$.

Government of the Northwest Territories. 2014v. "Extended Health Benefits for Specified Disease Conditions." Retrieved May 20, 2015. <http://www.hss.gov.nt.ca/health/nwt-health-care-plan/extended-health-benefits-specified-disease-conditions $>$.

Government of Yukon. 2005. “Yukon Health Guide: Drug Review Process." Retrieved May 20, 2015. <http:// www.ykhealthguide.org/library/drug_review/>.

Government of Yukon. 2013r. “ONLINE Yukon Drug Formulary.” Retrieved May 20, 2015. <http://www.hss.gov. yk.ca/drugformulary.php>.

Government of Yukon. 2013s. “Exception Drug Status." Retrieved May 20, 2015. <http://www.hss.gov.yk.ca/pdf/ yukon_drug_programs_formulary-exceptiondrugstatus.pdf > .

Grima, D.T. and I.A. Samjoo 2013. “Lessons Learned from the Dedicated Oncology Drug Review Process (pCODR) in Canada." < https://reimbursementdecisions.com/pdf_files/PCN141_Lessons_Poster.pdf>.

Health Canada. 2012a. "An Orphan Drug Framework for Canada." Retrieved May 20, 2015. <http://www.hc-sc. gc.ca/ahc-asc/media/nr-cp/_2012/2012-147a-eng.php>. 
Health Canada. 2012h. "First Nations \& Inuit Health. Provider Guide for Pharmacy Benefits." Retrieved May 20, 2015. <http://www.hc-sc.gc.ca/fniah-spnia/pubs/nihb-ssna/_drug-med/2010-prov-fourn-guide/index-eng. php\#a24>.

Health Canada. 2012i. “First Nations \& Inuit Health. Procedures for Appeals." Retrieved May 20, 2015. <http:// www.hc-sc.gc.ca/fniah-spnia/nihb-ssna/benefit-prestation/appe/index-eng.php>.

Health Canada. 2013q. "First Nations \& Inuit Health. Introduction - Drug Benefit List 2013." Retrieved May 20, 2015. <http://www.hc-sc.gc.ca/fniah-spnia/nihb-ssna/provide-fournir/pharma-prod/med-list/introduction-eng. php $>$.

Health Canada. 2013t."First Nations \& Inuit Health. Non-insured Health Benefits for First Nations and Inuit." Retrieved May 20, 2015. <http://www.hc-sc.gc.ca/fniah-spnia/nihb-ssna/index-eng.php>.

Hollis, A. 2005. “Drugs for Rare Diseases: Paying for Innovation.” In C.M. Beach, R. Chaykowski, R. Shortt, F. St-Hilaire and A. Sweetman, eds., Health Services Restructuring in Canada: New Evidence and New Directions. Proceedings of a Conference Held at Queen's University, November 17-18, (pp. 155-77). Montreal: Institute for Research on Public Policy (IRPP). Retrieved May 20 2015. <irpp.org/wp-content/uploads/2006/12/hollis.pdf>.

INESSS. 2007a. "Selecting Medication for Coverage in Quebec: A Responsible, Transparent Process. Information on the Scientific Evaluation Process of Medication." Retrieved May 20, 2015. <http://www.inesss.qc.ca/fileadmin/ doc/INESSS/DocuAdmin/Selecting-medication-coverage.pdf $>$.

INESSS. 2014b. “Evaluation Process and Criteria." Retrieved May 20, 2015. <http://www.inesss.qc.ca/index. php?id=39\&L=1>.

INESSS. 2014t. "Priority Evaluations." Retrieved May 20, 2015. <http://www.inesss.qc.ca/index. php?id $=40 \& \mathrm{~L}=1>$.

INESSS. 2014x. "Transitional Scientific Committee on Entry on the List of Medications/Comité scientifique permanent de l'évaluation des médicaments aux fins d'inscription." Retrieved May 20, 2015. <http://www.inesss. qc.ca/index.php?id $=27 \& \mathrm{~L}=1>$.

Manitoba Health. 2008."Pharmacare EDS Part 3 Coverage Request." Retrieved May 20, 2015. <www.gov.mb.ca/ health/mdbif/docs/edsnotice.pdf >.

Manitoba Health. 2014a. "Manitoba Drug Benefits and Interchangeability Formulary." Manitoba Drug Formulary Review Process. Retrieved May 20, 2015. <http://www.gov.mb.ca/health/mdbif/review.html>.

Manitoba Health. 2014b "Manitoba Drug Benefits and Interchangeability Formulary." Submission Requirements. Retrieved May 20, 2015. <http://www.gov.mb.ca/health/mdbif/sub.html\#2>.

Manitoba Blue Cross. 2014c. “Manitoba Blue Cross: Resources." Retrieved May 20, 2015. <http://www. mb.bluecross.ca/resources/faq $>$.

McArthur, D. 2013. Challenges and Innovations: Patented Drug Pricing and Coverage: A Funder's Perspective [presentation]. Toronto, ON: Ontario Public Drug Program. <http://www.slideshare.net/Pharmacare2020/dianemcarthur-pharmacare-2020-diane-mcarthur-feb-26-2013-final-16780765>.

Menon, D., T. Stafinski and G. Stuart. 2005. “Access to Drugs for Cancer: Does Where You Live Matter?” Canadian Journal of Public Health 96(6): 454-58.

Newfoundland \& Labrador Health \& Community Services. 2009. "Special Authorization Request Form." Retrieved May 20, 2015. <http://www.health.gov.nl.ca/health/prescription/standard_specauth_form.pdf>. Newfoundland \& Labrador Health \& Community Services. 2013n. "Prescription Drug Program (NLPDP)." Retrieved May 20, 2015. <http://www.health.gov.nl.ca/health/prescription/index.html>.

Newfoundland \& Labrador Health \& Community Services. 2014a. "Criteria for the Coverage of Special Authorization Drugs." Retrieved May 20, 2015. <http://www.health.gov.nl.ca/health/nlpdp/criteria.pdf>.

Nova Scotia Pharmacare. 2012j. Pharmacists' Guide. Retrieved May 20, 2015. <http://novascotia.ca/dhw/pharmacare/documents/Pharmacare-Pharmacists-Guide.pdf $>$.

Nova Scotia Health \& Wellness. 2013j. Nova Scotia Pharmacare. About Us. Retrieved May 20, 2015. <http:// novascotia.ca/dhw/pharmacare/about.asp $>$.

Nova Scotia Health \& Wellness. 2013k. Nova Scotia Pharmacare. Benefits and Reimbursement. Halifax (NS): Nova Scotia Pharmacare. Retrieved from <http://novascotia.ca/dhw/pharmacare/benefits-and-reimbursement.asp $>$. 


\section{Reimbursement of Drugs for Rare Diseases through the Public Healthcare System in Canada: Where Are We Now?}

Nunavut. 2007b. “Extended Health Benefits Policy." Retrieved May 20, 2015. <http://www.gov.nu.ca/information/policies>.

Ontario Ministry of Health and Long-Term Care (MOHLTC). 2000."Ontario Guidelines for Drug Submission and Evaluation." Retrieved May 20, 2015. <http://www.health.gov.on.ca/en/pro/programs/drugs/drug_submissions/guideline_templates.asp $x>$.

Ontario Ministry of Health and Long-Term Care (MOHLTC). 2011a. "Compassionate Review Policy." Retrieved May 20, 2015. <http://www.health.gov.on.ca/en/pro/programs/drugs/pdf/compassionate_review_policy.pdf>.

Ontario Ministry of Health and Long-Term Care (MOHLTC). 2011b.“Drugs for Rare Diseases (DRD) Screening Template." Retrieved May 20, 2015. <http://www.health.gov.on.ca/en/pro/programs/drugs/how_ drugs_approv/docs/drd_screening_template.pdf $>$.

Ontario Ministry of Health and Long-Term Care (MOHLTC). 2011c. “Compassionate Review Drug Policy Expanded: Ontario Providing Greater Access to Critical Drugs." Retrieved May 20, 2015. < http://www.health.gov. on.ca/en/news/bulletin/2011/compassionate_review.aspx>.

Ontario Ministry of Health and Long-Term Care (MOHLTC). 2011e."Drugs for Rare Diseases (DRD) Submission Template." Retrieved May 20, 2015. <http://www.health.gov.on.ca/en/pro/programs/drugs/how_ drugs_approv/docs/drd_submission_template.pdf $>$.

Ontario Ministry of Health and Long-Term Care (MOHLTC). 2012m. “Citizens' Council." Retrieved May 20, 2015. <http://www.health.gov.on.ca/en/public/programs/drugs/councils/>.

Ontario Ministry of Health and Long-Term Care (MOHLTC). 2013a. "Patient Evidence Submission." Retrieved May 20, 2015. <http://www.health.gov.on.ca/en/pro/programs/drugs/patient_evidence.aspx>.

Ontario Ministry of Health and Long-Term Care (MOHLTC). 2013c."How Drugs are Considered: Funding Decisions." Drugs for rare diseases (DRD). Retrieved May 20, 2015. <http://www.health.gov.on.ca/en/pro/programs/drugs/how_drugs_approv/review_rare_diseases.aspx $>$.

Ontario Ministry of Health and Long-Term Care (MOHLTC). 2013e. “Ontario Public Drug Programs. How Drugs are Approved." Retrieved May 20, 2015. <http://www.health.gov.on.ca/en/pro/programs/drugs/how_ drugs_approv/how_drugs_approv.aspx $>$.

Ontario Ministry of Health and Long-Term Care (MOHLTC). 2013h."How Drugs are Considered: Funding Decisions. Types of Funding Recommendations." Retrieved May 20, 2015. <http://www.health.gov.on.ca/english/ providers/program/drugs/how_drugs_approv/review_types.html>.

Ontario Ministry of Health and Long-Term Care (MOHLTC). 20131. “Ontario Public Drug Programs. Exceptional Access Program." Retrieved May 20, 2015. < http://www.health.gov.on.ca/en/pro/programs/drugs/ eap_mn.aspx>.

Ontario Ministry of Health and Long-term Care (MOHLTC). 2013p. “Understanding the Inherited Metabolic Diseases (IMD) Program." Retrieved May 20, 2015. < http://www.health.gov.on.ca/en/public/programs/drugs/ programs/imd.aspx $>$.

Ontario Ministry of Health and Long-term Care (MOHLTC). 2014w."The Ontario Drug Benefit (ODB)

Program." Retrieved May 20, 2015. <http://www.health.gov.on.ca/en/public/programs/drugs/programs/odb/odb. aspx>.

Ontario Ministry of Health and Long-Term Care (MOHLTC). 2014z."Exceptional Access Program (EAP) Reimbursement Criteria." Retrieved May 20, 2015. <http://www.health.gov.on.ca/en/pro/programs/drugs/ eap_criteria_list.aspx $>$.

Ontario Public Appointments Secretariat. 2013b. “Committee to Evaluate Drugs." Retrieved May 20, 2015. $<$ https://www.pas.gov.on.ca/scripts/en/boardDetails.asp?boardID=817>.

Panju, A.H. and C.M. Bell. 2010. “Policy Alternatives for Treatment of Rare Diseases." Canadian Medical Association Journal 182(7): E787-92.

PEI Ministry of Health \& Wellness. 2013f. "P.E.I. Pharmacare Formulary.” Retrieved May 20, 2015. <http://www. gov.pe.ca/photos/original/hpei_formulary.pdf >.

Picavet, E., D. Cassiman, C.E. Hollak, J.A. Maertens and S. Simoens. 2013. “Clinical Evidence for Orphan Medicinal Products - A Cause for Concern?" Orphanet Journal of Rare Diseases 8: 164. 
Regie de l'assurance maladie du Québec (RAMQ). 2013i. “List of medications.” Last updated on 15 November 2013. Retrieved May 20, 2015. <https://www.prod.ramq.gouv.qc.ca/DPI/PO/Commun/PDF/Liste_Med/ Liste_Med/liste_med_2013_11_15_en.pdf>.

Regie de l'assurance maladie du Québec (RAMQ). 2014i. “Prescription Drugs Covered by the Public Prescription Drug Insurance Plan." Retrieved May 20, 2015. <http://www.ramq.gouv.qc.ca/en/citizens/prescription-druginsurance/Pages/prescription-drugs-covered.asp $x>$.

Rocchi, A., E. Miller, R.B. Hopkins and R. Goeree. 2012."Common Drug Review Recommendations: An Evidence Base for Expectations?" Pharmacoeconomics 30(3): 229-46.

Saskatchewan Health. 2003. “Exception Drug Status Request." Retrieved May 20, 2015. <http://formulary.drugplan.health.gov.sk.ca/About.aspx >.

Saskatchewan Health. 2010d. "Request for Product Assessment." Retrieved May 20, 2015. <http://formulary. drugplan.health.gov.sk.ca/PDFs/ProductAssessmentForm.pdf>.

Saskatchewan Health. 2012g. “Drug Coverage Approved to Treat Rare Condition.” Press Release. Retrieved May 20, 2015. <http://www.saskatchewan.ca/government/news-and-media/2012/august/09/drug-coverage-approved-totreat-rare-condition $>$.

Saskatchewan Health. 2013g."Formulary; July 1, 2012-March 31, 2013." Retrieved May 20, 2015. <http://formulary.drugplan.health.gov.sk.ca/Publns/Formularyv62.pdf>.

Saskatchewan Health. 2013o. "Product Listing Agreements." Retrieved May 20, 2015. <http://formulary.drugplan. health.gov.sk.ca/PDFs/PLApolicy.pdf>.

Saskatchewan Health. 2014c. "Preface [Saskatchewan formulary]," Retrieved May 20, 2015. <http://formulary. drugplan.health.gov.sk.ca/PDFs/preface.pdf>.

Saskatchewan Health. 2014k. "About the Saskatchewan Formulary." Retrieved May 20, 2015. <http://formulary. drugplan.health.gov.sk.ca/About.aspx $>$.

Saskatchewan Health. 2014r. "Product Submission Process [flowchart]." Retrieved May 20, 2015. <http://formulary.drugplan.health.gov.sk.ca/PDFs/productsubmissionflowchart.pdf>.

Saskatchewan Health. 2014bb. "Inherited Metabolic Disease Benefits." Retrieved May 20, 2015. <http://formulary.drugplan.health.gov.sk.ca/PDFs/InheritedMetabolicDiseaseBenefitList.pdf>.

Saskatchewan Health. 2014cc. “Appendix A. Exception Drug Status Program." Retrieved May 20, 2015. <http:// formulary.drugplan.health.gov.sk.ca/PDFs/APPENDIXA.pdf>.

Shoppers Drug Mart. 2012b. “Manitoba Pharmacare Program.” Retrieved May 20, 2015. <http://www.drugcoverage.ca/en-ca/Provincial-Coverage/manitoba/drug-benefit-programs $>$.

Shoppers Drug Mart. 2014y. Yukon Insured Health Services. Retrieved May 20, 2015. <http://www.drugcoverage. $\mathrm{ca} /$ en-ca/Provincial-Coverage/yukon/drug-benefit-programs $>$.

Singh, R. 2012. Canada's Patchwork of 'Orphan' Drug Policies. Surrey: Pharmaphorum. <http://www.pharmaphorum.com/articles/canadas-patchwork-of-orphan-drug-policies >.

Spitz, S. 2013. “A Decade of the Common Drug Review." Canadian Medical Association Journal 185(7): E277-78.

West, M., K. Lemoine, C. Simms and S. Dyack. 2002، "Cross-Sectional Analysis of Renal Disease in the Nova Scotia Fabry Disease Kindred." Acta Paediatrica 91: 126.

Winquist, E., C.M. Bell, J.T. Clarke, G. Evans, J. Martin, M. Sabharwal et al. 2012."An Evaluation Framework for Funding Drugs for Rare Diseases." Value in Health 15(6): 982-86. 